\title{
Predictors of strong sense of coherence and positive attitudes to physical education in adolescents
}

\author{
ANN-CHRISTIN SOLLERHED ${ }^{1}$, GÖRAN EJLERTSSON ${ }^{2} \&$ ERWIN APITZSCH $^{3}$ \\ ${ }^{1}$ Department of Humanities and Social Sciences, Kristianstad University, Kristianstad, Sweden, and Department of \\ Community Medicine, Lund University, Sweden, ${ }^{2}$ Department of Health Sciences, Kristianstad University, Kristianstad, \\ Sweden, and ${ }^{3}$ Department of Psychology, Lund University, Lund, Sweden.
}

\begin{abstract}
Aims: The aim of this study was to find variables related to positive attitudes to physical education (PE) and strong sense of coherence (SOC) among adolescents. Methods: The study included three parts: seven physical tests; a questionnaire which included ways of living, attitudes to PE, and subjective health, the 13-question version of SOC; and information on every student's grades. The study group comprised 301 teenagers (131 girls and 170 boys, aged 16-19 years) attending upper secondary school. Positive odds ratio was used in the logistic regression analyses with SOC and attitudes to PE as dependent variables. Results: Variables related to positive attitudes to PE were strong SOC, high physical capacity, high leisure-time variables. Results: Variables related to positive attitudes to PE were strong SOC, high physical capacity, high leisure-time
physical activity (PA), high grades in PE, and little time spent watching TV. Variables related to strong SOC were positive attitudes to PE, high grades in PE, very good subjective health, and feeling comfortable in school. Highest physical capacity, highest mean grades, and highest grades in PE were found among adolescents who reported exercise four times or more per week. Conclusions: An interrelation between attitudes to PE and SOC was shown. The relation between positive attitudes to $\mathrm{PE}$ and high scores in SOC indicated that past experiences of PA and PE could contribute to the development of SOC, and actual levels of SOC could influence the persistent attitudes to PE and be important for lifelong PA. One means of identification of favourable or unfavourable health behaviour among young people might be through PA patterns, and relations between attitudes to PE and SOC.
\end{abstract}

Key Words: Adolescence, enjoyment, physical activity, physical education, physical fitness, positive attitudes, sense of coherence (SOC), subjective health

\section{Background}

Physical activity (PA) may influence the health of children and adolescents in two ways. First it influences health status during youth and second there seems to be a carry-over effect into adulthood, where improved adult health status results from childhood PA [1]. Besides the physical benefits, childhood PA is important from a behavioural perspective. Attitudes towards PA are formed in youth and seem to continue into adulthood [2].

Schools are the primary societal institutions with responsibility for promoting $\mathrm{PA}$ in young people, and school physical education (PE) is seen as an ideal site for this $[3,4]$. It has been shown that attitudes had a direct effect on intention to participate in physical education (PE) lessons [5].

Motivation for PE was correlated with participation in sport after school [6]. Leisure sports activities, positive attitudes to PA, and sports in adolescence were significant determinants of adult biological risk factors, for example cardiovascular risk [7]. There was an increase in body weight and a decrease in aerobic fitness among adolescents in Sweden in 1995 compared with 1974 [8]. Adolescents attending vocational programmes that lead to occupations involving physical effort had lower physical capacity than adolescents in theoretical programmes [9].

$\mathrm{PA}$ is a behaviour that today can be thought of as being under volitional control. It is possible to be

Correspondence: Ann-Christin Sollerhed, Department of Humanities and Social Sciences, Kristianstad University, 29188 Kristianstad, Sweden. Tel: +4644 2033 32. Fax: +46442033 03. E-mail: ann-christin.sollerhed $@$ husa.hkr.se

(Accepted 20 October 2004)

ISSN 1403-4948 print/ISSN 1651-1905 online/05/050334-9 \& 2005 Taylor \& Francis

DOI: $10.1080 / 14034940510005833$ 
Ann-Christin Sollerhed

active or sedentary and the attitude to PA is important. Attitudes develop through many sources. Direct experiences are important as well as socialization [10]. Though definitions vary, most attitude theories are about pros-cons, pleasant-unpleasant, like-dislike. The feeling of enjoyment is important for the interpretation of like or dislike of an activity [11] and reflects liking and fun [12]. Attitudes cannot determine behaviour unless they lead to intentions. The more personally relevant the attitude, the more likely it is to predict behaviour, to be consistent over time and to be resistant to change [10]. Intentions are determined not only by attitudes but also by social norms. Social norms influence the degree to which children wish to comply with the beliefs and actions of key people around them. Social norms represent social influence from parents, teachers, peers etc. [4].

Enjoyment has been found to be a major reason why young people engage in PA [13], and has been suggested to be a key construct in explaining the motivation and experiences of sport and exercise participants [14]. Intrinsically motivated activities are those characterized by enjoyment and no external rewards are needed to continue the behaviour [15]. Intrinsic motivation and flow are related and the balance between skills and challenge is important [16]. Vallerand proposed a model of motivation, wherein social factors were important for the motivation [17].

The grades in PE in adolescence have been shown to be important for the PA in adulthood [18]. PA was shown to be differentially associated with different sedentary pursuits such as watching television, playing video games etc. [19].

The concept Sense of Coherence (SOC), propounded by Antonovsky, is proposed as a personal orientation that expresses the way the individual responds to stress in life. SOC contains the subcomponents manageability, comprehensibility, and meaningfulness. Manageability is how an individual finds ways to cope with perceived strain in life. Comprehensibility is how an individual perceives the demands in life to be clear and structured. Meaningfulness is seen as the motivational component, the way the individual sees life with its purposes and challenges [20].

All three subcomponents are essential to the SOC. The motivational component meaningfulness seems to be especially important, because without this subcomponent the other two, manageability and comprehensibility, will not be persistent. People with high motivation are often committed to what they do and find resources and ways to do it. The SOC is mainly developed during childhood and adolescence [21]. SOC may influence the perceived strain and health in three ways. SOC influences whether a stimulus is appraised as a stressor or not, SOC influences the extent to which a stressor leads to tension or not, and SOC influences the extent to which tension is perceived as stress that leads to adverse health consequences [21]. Some persons maintain and even improve their health despite a high stressor load. The SOC concept has links to Kobasa's hardiness concept, which is seen as a composite of three intertwined components: commitment, control, and challenge [22].

The role of SOC in child and adolescent health is largely unexplored. Very few studies have been undertaken with adolescents and SOC. Results from a Swiss study suggest a certain degree of stability of SOC in middle to late adolescence. The SOC scale scores almost reached levels seen in adults and remained relatively stable over time among adolescents [23]. SOC may potentially be a salutogenic factor in adolescents' adaptation to school-related stress [24]. As a strong SOC predicted good health in men and women, SOC can be interpreted as an autonomous internal resource contributing to a favourable development of subjective state of health [25].

Searching for studies with adolescents and SOC in databases has given few results, and to the best of our knowledge no study has related SOC in adolescence to attitudes and behaviour in PA.

\section{Aims}

The aim of the present study was to find variables related to positive attitudes to physical education and strong sense of coherence among adolescents.

\section{Method}

The study group comprised 301 teenagers (131 girls and 170 boys, aged 16-19 years). These adolescents attended different educational programmes in upper secondary schools in southern Sweden. Students came from both the city and the surrounding countryside. The study was performed in autumn 1996.

Upper secondary school in Sweden consists of 16 different educational programmes, 14 vocational programmes leading to practical occupations and two theoretical programmes leading to university studies. Approximately $98 \%$ of all teenagers in Sweden attend these programmes. In all, the teenagers in this study (355 students, of whom 301 
[85\%] were present on the test day) attended eight of these 16 different national programmes. The two theoretical programmes (119 students) and six vocational programmes were represented (236 students). The vocational programmes were selected as they lead to occupations with high physical demands (e.g. building workers, assistant nurses, mechanics, food workers, industry workers).

A questionnaire was used that included leisuretime activities, ways of living, and attitudes to PE in school. The questionnaire was tested in a pilot study and adjusted before use. SOC was assessed by the 13-question version constructed by Antonovsky [20], and information on every student's grades was collected. Body height and body weight were measured and body mass index (BMI), weight height $^{2}\left(\mathrm{~kg} / \mathrm{m}^{2}\right)$ was calculated.

Physical capacity among adolescents was calculated as an individual standardized index, a $\mathrm{z}$ score, from the measured results in the seven physical tests containing maximal oxygen uptake, muscular strength, flexibility, and balance. These seven tests were chosen because they were possible to carry out in field testing in the schools, and were presumed to give a spectrum of the student's physical capacity [9]. All students were tested by the same test leader (ACS) and performed in the same order.

\section{Definitions}

Physical index. The physical index was calculated as $\Sigma\left(\mathrm{x}_{\mathrm{i}}-\overline{\mathrm{x}}_{\mathrm{i}}\right) / \mathrm{s}_{\mathrm{i}}$, where $\mathrm{i}$ was the number of the test from one to seven, $x_{i}$ was the individual's result for test number $i, \bar{x}_{i}$ was the group mean and $s_{i}$ was the standard deviation for test $i$, for girls and boys respectively. The standardized physical index was distributed around the mean 0 . A high physical index indicated high physical capacity for the individual, and a low index indicated low capacity [9].

Attitudes to PE. Attitude to 10 statements, 5 of which were positive and 5 negative towards physical education (PE) in school, were recorded. The positive statements were: $\mathrm{PE}$ is a fun subject, $\mathrm{PE}$ is an interesting subject, $\mathrm{PE}$ is an important subject for future health, PE is a welcome break in schoolwork, $\mathrm{PE}$ is a solidarity-creating subject. The negative statements were: $\mathrm{PE}$ is a boring subject, $\mathrm{PE}$ is an uninteresting subject, $\mathrm{PE}$ is an unimportant subject for future health, PE is an unnecessary subject which could leave space for other subjects instead, PE is a competition-creating subject. These 10 statements were arranged in opposite pairs in the statistical analyses. The positive/negative statements about $\mathrm{PE}$ as a solidarity-creating subject, or PE as a competitive subject, were excluded because of too few individuals.

Attitude to PE index. An index was calculated for each individual, where agreement with the positive statements and disagreement with the negative statements above was scored as +1 . Agreement with negative and disagreement with positive statements was scored as -1 . The index thus ranged from +10 to -10 . The attitude to $\mathrm{PE}$ index was dichotomized as closely as possible to the median value.

Self-reported exercise in leisure-time. The item in the questionnaire was: "How often do you exercise in your leisure-time so you get sweaty and out of breath?" Four groups were formed out of the seven response categories: (1) Never or a few times a year; (2) A few times a month or once a week; (3) Two or three times a week; (4) Four times or more a week. A dichotomized variable was formed from those four groups according to the median: low PA group 1-2, and high PA group 3-4.

Mean grade. This was the mean of all given grades in the school subjects. All the grades were on a five-point scale, with 5 being the highest and 1 the lowest.

PE grade. This was the grade in physical education.

SOC. SOC scale scores were taken from the short version of Antonovsky's test (13 items) [20]. The scores on each question ranged from 1 to 7 , thus the SOC value ranged from 13 to 91 .

Subjective health. This was measured by the answers to the item "How do you feel?" with the five response categories "very good, fairly good, neither good nor bad, fairly bad, very bad".

Feeling comfortable in school. This was measured by the answer to the item "How do you feel in school?" with the five response categories "very good, fairly good, neither good nor bad, fairly bad, very bad".

Allocated time to PE. This comprised answers to the item "What do you think about the time allocated to $\mathrm{PE}$ in the curriculum?" with the five response categories "far too much, a little too much, just enough, a bit too little, far too little". Two groups were defined according to the median: those who thought there was too little time allocated for PE, and those who thought there was just enough or too much. 
Ann-Christin Sollerhed

Sense of coherence and positive attitudes to $P E$ in adolescents

Statistical methods

The significance of differences in qualitative variables was tested by the chi-squared test. Quantitative variables were tested by Student's $t$-test. Analysis of variance (ANOVA) was used for assessing the significance of differences between means in different groups. Multivariate analyses were carried out by means of the logistic regression model with positive/ negative attitude to $\mathrm{PE}$, or strong/weak SOC respectively as dependent variables. All variables were dichotomized in order to avoid subjective influence. Variables measured by ordinal scale or higher were dichotomized as close as possible to the median value. Because of numerical restrictions of the model and to avoid too large an internal dropout, the variables included in the logistic regression analyses were divided into three groups according to contents: ARE variables (description of being), DO variables (description of doing) and THINK variables (description of thinking). In keeping with the salutogenic perspective of the study, the outcome of the logistic regression analysis was expressed as positive odds ratio (POR) and 95\% confidence interval (CI). POR was calculated as the odds ratio, but by changing positive and negative outcome as far as the dependent variable as well as the explanatory variables are concerned [26,27]. The definitions of variables in the logistic regression can be seen in Table I. The level of significance was set to $p=0.05$. Data analyses were carried out using SPSS for Windows 10.0 .

The study was approved by the Committee on Ethics at the Faculty of Medicine, Lund University (LU 88-96).

\section{Results}

The mean value of the SOC scores in the group of adolescents $(n=285)$ was $62.6(\mathrm{SD}=10.50)$. There were no differences between the SOC scores of girls

Table I. Variables included in the logistic regression models presented in Tables IV and V.

\begin{tabular}{|c|c|c|c|c|c|}
\hline \multirow[b]{2}{*}{ Variable } & \multirow[b]{2}{*}{ Scale } & \multicolumn{4}{|c|}{ Dichotomized } \\
\hline & & $\begin{array}{c}\text { Lower } \\
\text { numerical code }\end{array}$ & Text & $\begin{array}{c}\text { Higher } \\
\text { numerical code }\end{array}$ & Text \\
\hline Attitude to PE Index & I & $<4$ & Negative & $\geqslant 4$ & Positive \\
\hline \multirow{2}{*}{\multicolumn{6}{|c|}{ ARE variables }} \\
\hline & & & & & \\
\hline Physical index & I & $\leqslant 0.41$ & Low & $>0.41$ & High \\
\hline Body mass index (BMI) & I & $\leqslant 22.30$ & Low & $>22.30$ & High \\
\hline Mean grade & I & $\leqslant 3.1$ & Low & $>3.1$ & High \\
\hline PE grade & I & $1-3$ & Low & $4-5$ & High \\
\hline Gender & $\mathrm{N}$ & & Female & & Male \\
\hline Educational programme & $\mathrm{N}$ & & Vocational & & Theoretical \\
\hline \multicolumn{6}{|l|}{ DO variables } \\
\hline Smoking & O: No $(1) \rightarrow$ Every day $(6)$ & $1-4$ & Low & $5-6$ & High \\
\hline Alcohol intake & $\mathrm{O}:$ Never $(1) \rightarrow$ Every day $(5)$ & $1-2$ & Low & $3-5$ & High \\
\hline $\begin{array}{l}\text { Self-reported exercise in } \\
\text { leisure-time }\end{array}$ & $\begin{array}{l}\text { O: Never }(1) \rightarrow \\
\text { Four times a week }(7)\end{array}$ & $1-3$ & Low & $4-7$ & High \\
\hline Food intake & $\begin{array}{l}\text { O: No meal }(0) \rightarrow \\
3 \text { meals a day }(3)\end{array}$ & $\leqslant 2$ & Low & 3 & High \\
\hline Drug use & $\mathrm{N}$ & & Yes & & No \\
\hline TV watching & $\mathrm{Q}$ & $\leqslant 2 \mathrm{~h} /$ day & Low & $>2 \mathrm{~h} /$ day & High \\
\hline \multicolumn{6}{|l|}{ THINK variables } \\
\hline Allocated time for PE & $\begin{array}{l}\text { O: Too much }(\mathbf{1}) \rightarrow \\
\text { Too little }(5)\end{array}$ & $1-3$ & Much & $4-5$ & Little \\
\hline Enough exercise in leisure time & $\begin{array}{l}\text { O: Yes completely (1) } \rightarrow \\
\text { No not at all }(4)\end{array}$ & $1-2$ & Yes & $3-4$ & No \\
\hline Enough exercise in $\mathrm{PE}$ & $\begin{array}{l}\text { O: Yes completely }(1) \rightarrow \\
\text { No not at all }(4)\end{array}$ & $1-2$ & Yes & $3-4$ & No \\
\hline PE appropriate for future work & $\begin{array}{l}\text { O: Yes completely }(1) \rightarrow \\
\text { No not at all }(4)\end{array}$ & $1-2$ & Yes & $3-4$ & No \\
\hline Feeling comfortable in school & $\begin{array}{l}\text { O: Very good }(1) \rightarrow \\
\text { Very bad }(5)\end{array}$ & 1 & Very good & $2-5$ & Not very good \\
\hline Subjective health & $\begin{array}{l}\text { O; Very good }(1) \rightarrow \\
\text { Very bad }(5)\end{array}$ & 1 & Very good & $2-5$ & Not very good \\
\hline
\end{tabular}

$\mathrm{N}=$ nominal, $\mathrm{O}=$ ordinal, $\mathrm{I}=$ interval, $\mathrm{Q}=$ quote. 
$(n=127), 62.8(\mathrm{SD}=10.01)$ and boys $(n=158), 62.4$ ( $\mathrm{SD}=10.91 ; p=0.788)$. Comparison between girls' and boys' scores in the subcomponents (girls $n=128-129$; boys $n=159-167$ ) showed differences. Girls had higher scores on meaningfulness, 21.2 $(\mathrm{SD}=3.57)$ compared with boys, $19.8(\mathrm{SD}=4.26$; $p=0.004$ ) and boys had higher scores on manageability, $20.0(\mathrm{SD}=4.48)$, compared with girls, 18.9 $(\mathrm{SD}=4.07 ; p=0.045)$. No difference in the score of the subcomponent comprehensibility was found: boys $23.5(\mathrm{SD}=5.56)$ and girls $23.5(\mathrm{SD}=5.22$ $p=0.938$ ).

The mean score in SOC differed between positive statements and negative statements to PE concerning enjoyment, interest, and necessity. The scores in the subcomponent meaningfulness differed between positive and negative statements, but no differences were found concerning the two other components, manageability and comprehensibility (Table II),

Adolescents who agreed with positive statements reported PA in leisure-time to a higher exten compared with their peers who agreed with negative statements. The physical index was higher among students who agreed with positive statements and those students also thought the allocated time for PE was insufficient (see Table II).

The physical index was related to self-reported PA. The index was high among adolescents who

Table II. Positive and negative statements about PE and the corresponding group mean of SOC, meaningfulness, manageability, comprehensibility, and physical index, percentage of high self-reported PA in leisure-time, and interpretation of allocated PE $(n=301)$.

\begin{tabular}{|c|c|c|c|}
\hline Variables & Positive statement & Negative statement & $p$-value \\
\hline \multicolumn{4}{|c|}{ Enjoyment } \\
\hline$n$ & $\begin{array}{l}\text { PE is fun } \\
(153-172)\end{array}$ & $\begin{array}{c}\mathrm{PE} \text { is boring } \\
(34-38)\end{array}$ & \\
\hline soc & 64.1 & 59.5 & 0.019 \\
\hline Meaningfulness & 20.9 & 18.8 & 0.006 \\
\hline Manageability & 19.9 & 18.7 & 0.130 \\
\hline Comprehensibility & 23.9 & 23.6 & 0.774 \\
\hline Physical Index & 1.01 & -2.33 & $<0.001$ \\
\hline High PA (\%) & 64 & 24 & $<0.001$ \\
\hline Too little time allocated for PE (\%) & 81 & 19 & $<0.001$ \\
\hline \multicolumn{4}{|l|}{ P } \\
\hline$n$ & $\begin{array}{l}\mathrm{PE} \text { is interesting } \\
(64-69)\end{array}$ & $\begin{array}{l}\mathrm{PE} \text { is uninteresting } \\
(24-27)\end{array}$ & \\
\hline SOC & 62.9 & 58.1 & 0.046 \\
\hline Meaningfulness & 20.8 & 18.3 & 0.008 \\
\hline Manageability & 19.6 & 18.3 & 0.173 \\
\hline Comprehensibility & 23.2 & 23.5 & 0.841 \\
\hline Physical index & 0.58 & -2.52 & 0.001 \\
\hline High PA (\%) & 67 & 26 & $<0.001$ \\
\hline Too little time allocated for PE (\%) & 81 & 15 & $<0.001$ \\
\hline \multicolumn{4}{|c|}{ Importance } \\
\hline & $\mathrm{PE}$ is important & $\mathrm{PE}$ is unimportant & \\
\hline$n$ & $(137-149)$ & $(17-20)$ & \\
\hline SOC & 63.4 & 60.1 & 0.208 \\
\hline Meaningfulness & 20.9 & 18.9 & 0.048 \\
\hline Manageability & 19.4 & 19.1 & 0.766 \\
\hline Comprehensibility & 23.9 & 24.2 & 0.786 \\
\hline Physical index & 0.24 & -1.39 & 0.078 \\
\hline High PA (\%) & 51 & 47 & 0.478 \\
\hline \multirow{2}{*}{\multicolumn{4}{|c|}{ 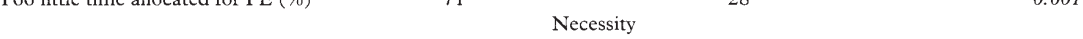 }} \\
\hline & & & \\
\hline & $\mathrm{PE}$ is welcome & $\mathrm{PE}$ is unnecessary & \\
\hline$n$ & $(143-162)$ & $(15-18)$ & \\
\hline SOC & 64.2 & 58.3 & 0.023 \\
\hline Meaningfulness & 21.0 & 18.5 & 0.008 \\
\hline Manageability & 20.1 & 18.6 & 0.166 \\
\hline Comprehensibility & 24.0 & 23.2 & 0.531 \\
\hline Physical index & 0.76 & -2.50 & 0.001 \\
\hline High PA (\%) & 57 & 22 & 0.005 \\
\hline Too little time allocated for PE (\%) & 80 & 11 & $<0.001$ \\
\hline
\end{tabular}

Number of adolescents who agreed with the statement; $n$-values can differ between the variables because of internal dropout; range of $n$ value in parentheses; $p$-value in italics when significant. 
Ann-Christin Sollerhed

reported regular PA. The highest physical index (1.8) was found among adolescents who reported regular exercise four times or more a week, and the lowest $(-3.5 ; p<0.001)$ among adolescents who reported no exercise in leisure-time. The grade in PE was related to self-reported $\mathrm{PA}$, the highest $\mathrm{PE}$ grades being among those who reported exercise four times or more per week (3.9) and the lowest among those who reported no exercise (2.6; $p<0.001)$. The same relation could be seen concerning the total mean grades, 3.3 and 2.8 respectively $(p=0.003)$. No differences were found between boys and girls in any of the variables (Table III).

The relationship between attitudes to $\mathrm{PE}$ and the "ARE, DO, THINK variables", defined in Table I, was studied in logistic regression analyses. High physical index $(\mathrm{POR}=2.8)$, strong SOC $(\mathrm{POR}=2.1)$ and high grade in $\mathrm{PE}(\mathrm{POR}=2.2)$ were significantly related to positive attitudes to PE among the ARE variables. Among "DO variables", high frequency of self-reported exercise in leisure-time $(\mathrm{POR}=2.3$ ) and little time spent watching TV $(\mathrm{POR}=2.1)$ were significant. Furthermore, a relation between positive attitudes and opinions concerning insufficient time allocated to PE in school was found $(\mathrm{POR}=5.7)$. The other variables were not significantly related to attitudes towards PE in the analyses (Table IV).

Variables related to high scores in SOC were high grade in $\mathrm{PE}(\mathrm{POR}=2.1)$, very good subjective health $(\mathrm{POR}=2.8)$, feeling comfortable in school $(\mathrm{POR}=2.6)$ and positive attitudes to $\mathrm{PE}(\mathrm{POR}=1.8)$ according to Table $\mathrm{V}$.

Table III. Self-reported physical exercise in leisure-time among adolescents and corresponding physical index, SOC, mean grade, PE grade, and attitude to PE inde

\begin{tabular}{lccccc}
\hline Self-reported exercise & Physical index & SOC & Mean grade & PE grade & Attitude to PE index \\
\hline Never/a few times a year $(n=41)$ & -3.5 & 60.5 & 2.8 & 2.6 & -0.1 \\
A few times a month/once a week $(n=104)$ & -0.2 & 62.6 & 3.2 & 3.2 & 3.7 \\
Twice/three times a week $(n=108)$ & 0.7 & 62.7 & 3.3 & 3.5 & 5.0 \\
Four times or more a week $(n=39)$ & 1.8 & 64.2 & 3.3 & 3.9 & 4.1 \\
p-value & $<0.001$ & 0.495 & 0.003 & $<0.001$ & $<0.001$ \\
\hline
\end{tabular}

Significance of differences tested by ANOVA.

Table IV. Positive odds ratios (POR) and 95\% confidence intervals (CI) for predictors of positive attitudes to physical education (PE): results from logistic regression analyses.

\begin{tabular}{lcl}
\hline Variables & POR & $95 \% \mathrm{CI}$ \\
\hline ARE variables & $(n=214)$ & \\
Physical index - high & 2.8 & $1.5-5.4$ \\
BMI - low & 0.82 & $0.45-1.5$ \\
Sense of coherence scores - high & 2.1 & $1.1-3.8$ \\
Mean grade - high & 0.79 & $0.37-1.7$ \\
PE grade - high & 2.2 & $1.1-4.4$ \\
Gender - male & 0.62 & $0.32-1.2$ \\
Educational programme -theoretical & 1.1 & $0.56-2.3$ \\
DO variables & $(n=265)$ & \\
Smoking - low & 1.7 & $0.99-3.1$ \\
Alcohol intake - low & 0.67 & $0.34-1.3$ \\
Self-reported exercise - high & 2.3 & $1.3-3.8$ \\
Food intake - high & 0.66 & $0.38-1.1$ \\
Drug use - no & 1.1 & $0.66-1.9$ \\
TV watching - low & 2.1 & $1.2-3.6$ \\
THINK variables & $(n=286)$ & \\
Allocated time for PE - little & 5.7 & $3.2-10$ \\
Enough exercise in leisure time - yes & 1.2 & $0.68-2.0$ \\
Enough exercise in PE - no & 1.1 & $0.54-2.1$ \\
PE appropriate for future work - no & 0.87 & $0.50-1.5$ \\
Feeling comfortable in school - very good & 1.4 & $0.79-2.5$ \\
Subjective health - very good & 1.4 & $0.76-2.4$ \\
\hline
\end{tabular}

POR in italics when significant. 
Table V. Positive odds ratios (POR) and 95\% confidence intervals (CI) for predictors of high scores in SOC. Results from logistic regression analyses.

\begin{tabular}{lcc}
\hline Variables & POR & $95 \%$ CI \\
\hline ARE variables & $(n=219)$ & \\
Physical index - high & 0.94 & $0.51-1.7$ \\
BMI - low & 0.98 & $0.57-1.7$ \\
Mean grade - high & 0.94 & $0.49-1.8$ \\
PE grade - high & 2.1 & $1.1-3.8$ \\
Gender - male & 1.1 & $0.60-1.9$ \\
Educational programme - theoretical & 1.1 & $0.56-2.0$ \\
DO variables & $n=273)$ & \\
Smoking - low & 1.3 & $0.78-2.2$ \\
Alcohol intake - low & 1.4 & $0.75-2.7$ \\
Self-reported exercise - high & 1.4 & $0.87-2.3$ \\
Food intake - high & 1.2 & $0.73-2.0$ \\
Drug use - no & 1.4 & $0.83-2.2$ \\
TV watching - low & 0.94 & $0.52-1.7$ \\
THINK variables & $(n=271)$ & \\
Allocated time for PE - little & 1.2 & $0.65-2.3$ \\
Enough exercise in leisure time - yes & 1.1 & $0.62-1.8$ \\
Enough exercise in PE - no & 1.7 & $0.85-3.6$ \\
PE appropriate for future work - no & 1.3 & $0.73-2.2$ \\
Feeling comfortable in school -very good & 2.6 & $1.5-4.5$ \\
Subjective health -very good & 2.8 & $1.6-5.0$ \\
Attitude to PE index - positive & 1.8 & $1.0-3.3$ \\
\hline
\end{tabular}

POR in italics when significant

\section{Discussion}

The present study showed positive relationships between SOC and attitudes to PE, between attitudes to PE and PA in leisure-time, and between PA and physical capacity among adolescents. Even if no conclusion about the causality can be drawn, these findings are challenging. Variables related to high scores in SOC were very good subjective health and feeling comfortable in school, high grade in $\mathrm{PE}$, and positive attitudes to $\mathrm{PE}$. The $\mathrm{PE}$ grade was significantly related to the SOC level but not the total mean grades. Subjective health and feeling comfortable in school can be seen as a natural prediction for high levels in SOC, which is in accordance with other studies, but the influence from PE is startling. According to Antonovsky, SOC is mainly developed in childhood and adolescence [21]. Results presented in our study showed that SOC might influence the attitudes to $\mathrm{PE}$ and persistent PA patterns. The reverse is also true: positive attitudes to $\mathrm{PE}$ and PA could influence the actual SOC among adolescents. The interrelation between SOC and attitudes to PE indicates that it might be possible to affect the development of SOC through positive experiences of PE in school. Social influence for the development of positive attitudes to PA has previously been shown in other studies [4]. Experiences from PA in childhood have been shown to influence the attitude to PA [2], and attitudes to
PA in adolescence to influence adult risk factors [7]. Our study implies that it might also affect the SOC level, which could be important for the motivation for lifelong PA and for improved adult health status.

Other variables related to positive attitudes to $\mathrm{PE}$ were high physical index, high grade in $\mathrm{PE}$, high frequency of PA, little TV watching, and opinions regarding insufficient time allocated for $\mathrm{PE}$, which all are aspects of activity. Adolescents with positive attitudes to PE seem to be active people as things are at present but they also want even more PE in school. They had higher scores in SOC, which could be an internal resource for a more favourable development of subjective state of health [25]. They also had higher scores in the subcomponent meaningfulness, defined as the motivational component in SOC [20]. No significant differences were found in the other two subcomponents. Adolescents with positive attitudes to $\mathrm{PE}$ can be seen as positive to PA in general, as they reported PA in leisure-time to a higher extent compared with their peers who agreed with negative statements about PE. Their physical capacity was high, which indicates that they actually were physically active. These adolescents might become physically active as adults [2], and chronic diseases may be reduced because of past and present PA.

Adolescents who reported exercise regularly not only had high physical capacity but also high grade 
Ann-Christin Sollerhed

in both PE and in the average points of all given school grades, and they were positive towards PE. They can be thought of as being intrinsically motivated in PA. Skills in balance with challenge are important for intrinsic motivation $[15,16]$. It is difficult to evaluate the adolescents' skills completely. Two indications of skills were used in this study, the grade in PE and the physical index from the measured physical test. Adolescents with low grade in PE did not seem to develop their physical qualities in leisure-time, or in PE, probably because of lack of motivation. Low skills become in themselves a demotivator, and high skills, on the other hand, motivate to conquer new challenges and strengthen the high motivation, which is in accordance with the theories of Csikzentmihalyi [16]. Intrinsically motivated behaviour was shown to be associated with perceived competence and feelings of self-determination [15] and the grades in PE in adolescence were important for the PA in adulthood [18]. From the perspective of future health behaviour, it is important to let children and adolescents experience a sense of competence and enjoyment in $\mathrm{PE}$ and raise their skills, which cannot be ignored by society and health strategists. In PE perceived competence is important, because some students do not have any past experiences of sports activities through their families [5]. The importance of the experiences of PE becomes then even more important for socialization into a physically active life, particularly with regard to reducing the inequality in physical capacity and health between blue-collar and white-collar workers [28], which can already be seen in school [9]. The association between emotional well-being and vigorous PA among adolescents has been shown in other studies [29], and the association between physical inactivity in adolescence has been shown to be associated with a less healthy lifestyle, worse educational progression, and poor self-perceived health [30]. Future health could be put forward as a very strong argument for PA but is not the main reason for activity among adolescents, who practise PA for enjoyment. Increased body weight and decreased aerobic fitness among adolescents in Sweden [8], and indications that negative attitudes to PA in adolescence were significant determinants of adult risk factors [7], strongly emphasize the importance of positive attitudes to PA in childhood and adolescence. School PE is one important arena for promotion according to results from our study.

PA is one activity among many others for a young person but is special in many ways. PA is connected with effort, and sometimes also with physical pain. However, many people perceive PA as pleasant and enjoy it. Kobasa showed that exercise combined with hardy personality and social support was very effective in preserving health [22]. Antonovsky as well as Kobasa focused on the salutogenic question why some people avoid becoming sick although they have high stress - and related it to hardiness [20]. Adolescents in our study who thought PE was fun were physically active in leisure-time, and had high levels on SOC. They can be thought of being both intrinsically motivated for PA and as having a certain level of hardiness. Adolescents with high levels on SOC, and positive attitudes to $\mathrm{PE}$ and PA are probably hardy people who are high in commitment and control, and regard challenges to be the norm and find them stimulating. They do not care if they get some occasional pain from PA and do not focus on the negative aspects. The levels in SOC among adolescents might represent the personality, together with the social influence from parents, teachers, peers, and other key people around them. Other studies have shown the importance of social influence for beliefs and actions, although not in the form of SOC [4,17]. Vallerand's model posits that the influence of social factors is exerted through the need for autonomy, competence, and relatedness [17]. SOC was interpreted as the autonomous internal resource [25] and reminds one of the model of Vallerand. Self-efficacy and attitude, which are strong predictors of PA intention, were influenced by past behaviour and experiences [13].

There was no difference in the scores of SOC between girls and boys in our study. The SOC scores were higher for both girls and boys compared with Israeli adolescents in Antonovsky's published studies [21]. The girls in our study had higher scores on the subcomponent meaningfulness than the boys, and the boys had higher scores in the subcomponent manageability than the girls. Though the total SOC score did not differ between girls and boys, the content of the SOC score differed through the subcomponents. It can be assumed that these slight differences might show that girls are more likely to see the meaning in life with its purposes more clearly, and that boys are more likely to find ways to cope with stressors in life and means to deal with different problems. However, this study cannot give the ultimate answer to this, and must leave it for future research.

The role of SOC in child and adolescent health is largely unexplored, which is why the results from our study are interesting, although the cross-sectional survey study design is a limitation to really shedding light on the matter. We talk about relations between variables and not about predictors as the directions of the relations are unclear. Advantages of the study 
are that it was population based, that it comprised different sources of information - questionnaires, physical tests and grades - and that the participation rate was comparatively high. Another advantage is the salutogenic perspective: the focus is on the positive influences on adolescents' health.

\section{Conclusion}

In the present study an interrelation between SOC and attitudes to PE among adolescents was shown. The relation between positive attitudes to $\mathrm{PE}$ and high scores in SOC indicated that past experiences of PA could contribute to the development of SOC, and that actual levels of SOC could influence the persistent attitudes to $\mathrm{PE}$ and be important for lifelong PA. Promotion of PA through PE is of great importance and efforts must be put into making early positive experiences in school PE contribute to positive attitudes to PA, reducing the inequality in health between different groups of the population. One means of identification of favourable or unfavourable health behaviour among young people might be PA patterns, and relations between attitudes to $\mathrm{PE}$ and SOC.

\section{References}

[1] Boreham C, Riddoch C. The physical activity, fitness and health of children. J Sports Sci 2001;19:915-29.

[2] Riddoch CJ, Savage JM, Murphy N, Cran GW, Boreham C. Long term health implications of fitness and physical activity pang term health implications of fitness and

[3] Sallis JF, McKenzie TL. Physical education's role in public health. Res Q Exerc Sport 1991;62:124-37.

[4] Biddle $\mathrm{SJH}$, Chatzisarantis N. Motivation for a physically active lifestyle through physical education. In: Vanden Auweele Y, editor. Psychology for physical educators. Champaign, IL: Human Kinetics, 1999.

[5] Papaionnou A, Theodorakis Y. A test of three models for the prediction of intention for participation in physical education prediction of intention for participation in phys

[6] Goudas M, Dermitzaki I, Bagiatis K. Motivation in physical education is correlated with participation in sport after school. Psychol Rep 2001;88:491-6.

[7] Barnekow-Bergqvist M, Hedberg G, Janlert U, Jansson E. Adolescent determinants of cardiovascular risk factors in adult men and women. Scand J Public Health 2001;29:208-17.

[8] Westerstâhl M, Barnekow-Bergkvist $M$, Hedberg G, Jansson E. Secular trends in sports: Participation and attitudes among adolescents in Sweden from 1974 to 1995. Acta Paediatr 2003;92:602-9.

[9] Sollerhed AC, Ejlertsson G. Low physical capacity among adolescents in practical education. Scand J Med Sci Sports 1999;9:249-56.

[10] Gazzaniga MS, Heatherton TF. Psychological science, mind, brain, and behaviour. New York: W.W. Norton, 2003.
[11] Ajzen I. Attitudes, personality and behaviour. Milton Keynes: Open University Press, 1988.

[12] Kimiecik J, Harris A. What is enjoyment? A conceptual definitional analysis with implications for sport and exercise psychology. J Sport Exerc Psychol 1996;18:247-63.

[13] Hagger MS, Chatzisarantis N, Biddle SJH. The influence of self-efficacy and past behaviour on the physical activity intentions of young people. J Sports Sci 2001;19:711-25.

[14] Wankel LM. The importance of enjoyment to adherence and psychological benefits from physical activity. Int J Sport Psychol 1993;24:151-69.

[15] Deci EL, Ryan RM. Intrinsic motivation and self-determination of human behaviour. New York: Plenum Press, 1985

[16] Csikszentmihalyi M. Beyond boredom and anxiety: Experiencing flow in work and play. 25th anniversary ed. San Francisco: Jossey-Bass, 2000

[17] Vallerand RJ. Toward a hierarchical model of intrinsic and extrinsic motivation. In: Zanna $M$, editor. Advances in extrinsic motivation. In: Zanna $M$, editor. Advances in
experimental social psychology. New York: Academic Press, 1997.

[18] Engström LM. Idrott som social markör [Sport as a social indicator] (in Swedish). Stockholm: HLS Förlag, 1999.

[19] Feldman DE, Barnett T, Shrier I, Rossignol M, Abenhaim L. Is physical activity differentially associated with different types of sedentary pursuits? Arch Pediatr Adolesc Med 2003;157:797-802.

[20] Antonovsky A. Unraveling the mystery of health. San Francisco: Jossey-Bass, 1987.

[21] Antonovsky A. The structure and properties of the sense of coherence scale. Soc Sci Med 1993;36:725-33.

[22] Kobasa SC, Maddi SR, Pucetti MC, Zola MA. Effectiveness of hardiness, exercise, and social support as recources against illness. J Psychosom Iilness 1985;29:525-33.

[23] Buddleberg-Fischer B, Klaghofer R, Schnyder U. Sense of coherence in adolescents. Soz Praventivmed 2001;46:404-10.

[24] Torsheim T, Aaroe LE, Wold B. Sense of coherence and school-related stress as predictors of subjective health complaints in early adolescence: Interactive, indirect or direct relationships? Soc Sci Med 2001;53:603-14.

[25] Souminen S, Helenius H, Blomberg H, Uutela A, Koskenvuo M. Sense of coherence as a predictor of subjective state of health: Results of 4 years follow-up of adults. J Psychosom Res 2001;50:77-86.

[26] Ejlertsson G, Edén L, Ledén I. Predictors of positive health in disability pensioners: A population-based questionnaire study using Positive Odds Ratio. BMC Public Health study using

[27] Ejlertsson G, Sollerhed A-C. Predictors of good quality of life in school children: A population-based Swedish study using a new concept, Positive Odds Ratio. Eur J Public Health 2002;12(Suppl.):53.

[28] Andersson I, Ejlertsson G, Leden I, Rosenberg C. Chronic pain in a geographically defined general population: Studies of differences in age, gender, social class, and pain. Clin J of differences in age,

[29] Steptoe A, Butler N. Sports participation and emotional wellbeing in adolescents. Lancet 1996;347: 1789-92.

[30] Aarnio M, Winter T, Kujala U, Kaprio J. Associations of health related behaviour, social relationships, and health status with persistent physical activity and inactivity: A study of Finnish adolescent twins. Br J Sports Med 2002;360-4. 